\title{
Evaporative Cooling as an Adjunct to Ice Bag Use after Resuscitation from Heat-Induced Arrest in a Primate Model
}

\author{
GIDEON M. ESHEL, PETER SAFAR, AND WILLIAM STEZOSKI \\ International Resuscitation Research Center, Department of Anesthesiology/Critical Care Medicine, and \\ Presbyterian-University Hospital, University of Pittsburgh, Pittsburgh, Pennsylvania 15260
}

\begin{abstract}
Heat stroke and other hyperthermia-related crises are serious clinical problems in childhood and adolescence. Rapid cooling is required to reduce morbidity and mortality. A variety of effective cooling methods exist, and some may interfere with monitoring and resuscitation or are not readily available. We studied in 12 pigtail monkeys the pathophysiology of immersion hyperthermia $\left(42^{\circ} \mathrm{C}\right)$ to cardiac arrest (1 min no flow) and CPR plus cooling to normothermia for restoration and stabilization of spontaneous normotension. This was followed by intractable shock and secondary arrest. These studies gave us the opportunity to compare two simple cooling methods applied during and after CPR: group I $(n=6)$ received application of ice bags to the groins, axillae, and neck. Group II $(n=6)$ received ice bags plus cold water wetting (sponging) over the entire anterior surface of trunk and extremities, plus fanning. CPR restored spontaneous circulation in four of six in each group, after CPR of 1.5-16 min (NS between groups). Speed of cooling correlated with speed of stabilization of spontaneous normotension. After cardiac arrest and during and after CPR, rectal temperature had declined from a lethal level of $42.2^{\circ} \mathrm{C}$ to a safe level of $38.5^{\circ} \mathrm{C}$ within $45 \pm 6(38-53) \mathrm{min}$ in group $\mathrm{I}$, and within $28 \pm 4(23-32) \mathrm{min}$ in group II $(p<0.05)$. Epidural and esophageal temperatures declined more rapidly than rectal temperature. For critical hyperthermia, we recommend immediate application of ice bags, cold water wetting (sponging), fanning, and head cooling combined when invasive blood cooling (the most effective method) is not immediately available (Pediatr Res 27:264-267, 1990)
\end{abstract}

\section{Abbreviations}

ALS, advanced life support

CPR, cardiopulmonary resuscitation

CVP, central venous pressure

ICP, intracranial pressure

IPPV, intermittent positive-pressure ventilation

MAP, mean arterial pressure

$\mathrm{PETCO}_{2}$, end-tidal partial pressure of $\mathrm{CO}_{2}$

Tep, epidural temperature

Tes, esophageal temperature

$\mathrm{Tr}$, rectal temperature
Hyperthermia-related crises are serious problems in infancy, childhood, and adolescence $(1,2)$. Hemorrhagic shock and encephalopathy related to hyperpyrexia is a relatively newly recognized syndrome in pediatric emergency medicine $(3,4)$. Febrile apnea has occurred occasionally in premature babies (5-7) and in infants and young children exposed to hot environments (8), usually between the ages of 2 and 8 mo $(1,9)$. Deaths due to heat-aggravated illness are probably more frequent in infants less than $1 \mathrm{y}$ of age than in any other age group less than $50 \mathrm{y}(10)$ Most deaths have occurred in a warm environment, as caused by fire, electric blanket, thick blankets, or swaddling (1, 11-13). Most deaths from garment-related hyperthermia in babies seem to occur during the winter (1). However, in adolescents environmentally related hyperthermic illness is more common during the hot season (14). Infants have suffered heat stroke in motor vehicles $(15-17)$.

The outcome of severe hyperthermia seems to depend on both duration and degree of hyperthermia $(18,19)$. Morbidity and mortality are high when cooling is delayed or ineffective $(20$ 22). Arterial hypotension in heat stroke can be corrected simply by rapidly restoring and maintaining normothermia, which may obviate the need for vasopressors or prolonged fluid therapy $(20$, 23). Convulsions, metabolic abnormalities, and arrhythmias also have sometimes responded merely to rapid restoration of normothermia (24).

Several methods are currently used to lower high body temperature. Their relative effectiveness has not been systematically examined. Some methods are simple, whereas others demand sophisticated skills or special equipment. All methods promote heat loss by conduction, convection, or evaporation. In general, once active surface cooling has reduced $\operatorname{Tr}$ to $38.5^{\circ} \mathrm{C}, \mathrm{T}$ continues to drift downward $(19,23,24)$. Recurrence of hyperthermia is rare.

Immersion in ice water with skin massage to prevent cutaneous vasoconstriction is in use $(19,24-26)$. Weiner and Khogali (27) found it to be less effective than evaporation in human volunteers. Nevertheless, ice water tubs are not always available, and monitoring, resuscitation, and defibrillation during submersion are difficult or impossible $(19,23)$. Electric cooling blankets are expensive and often not immediately available. A popular method involves applying ice bags to the groin, axillae, and neck, where large vessels are close to the surface $(28,29)$. Its limitations include vasoconstriction and local skin damage. Evaporative heat loss from the skin can be promoted by sponging with cold water $(18,26)$. Alcohol sponging in infants can produce hypoglycemia and CNS depression secondary to inhalation of alcohol fumes $(28,29)$. Fanning of the body surface, a simple and immediately available method, increases evaporative heat loss after sponging (26). Administration of cold fluids by mouth (8), rectum, bladder $(29,30)$, stomach $(31)$, or i.v. catheter $(8,15,32)$ is of adjunctive value.

We decided to study the effect of the simplest cooling techniques that are available in most emergency rooms, i.e. applying
Received June 9, 1989; accepted November 2, 1989.
Correspondence and reprint requests Dr. G. M. Eshel, International Resuscitation Research Center, University of Pittsburgh, 3434 Fifth Avenue, Pittsburgh, PA 15260.

Supported in part by the Pennsylvania Department of Health and the Asmunol S. Laerdal Foundation. G.M.E. was IRRC Research Fellow 1978/79. 
ice bags, and surface sponging with fanning. The experiments in which these observations were made are described elsewhere (33); they concern the pathophysiology of dying from hyperthermia, the acute resuscitability from hyperthermic cardiac arrest, and cerebral changes (unpublished data).

\section{MATERIALS AND METHODS}

Twelve pigtail monkeys, healthy young males and females $3-$ $5 \mathrm{~kg}$, were managed according to NIH regulations and the "Guiding Principles in the Care and Use of Animals" of the American Physiological Society. Food was provided up to $12 \mathrm{~h}$ before the experiments and water ad libitum. The monkeys were subjected to anesthesia, preparation, and immersion heating to Tep of $42^{\circ} \mathrm{C}$, as previously described (33). Surgical anesthesia was induced with $\mathrm{N}_{2} \mathrm{O}-\mathrm{O}_{2}$-halothane and the trachea was intubated. Then all hair was removed. Temperature probes were inserted $10 \mathrm{~cm}$ into the rectum (Tr), into the lower esophagus (Tes), and into the epidural space (Tep). A catheter for monitoring the ICP was inserted supracortically. ECG electrodes were attached, and urinary and gastric catheters were inserted. Cannulas were placed via femoral artery into the aorta and via a femoral vein into the inferior vena cava, for pressure monitoring and blood sampling. Glucose $5 \%$ in $\mathrm{NaCl} 0.45 \%, 3-5 \mathrm{~mL} / \mathrm{kg} / \mathrm{h}$, was given during preparation and discontinued during hyperthermia. Continuously monitored were: MAP, CVP, EEG, ICP, ECG, PETCO ${ }_{2}$, Tr, Tes, and Tep. Light anesthesia was maintained with ketamine, about $10 \mathrm{mg} / \mathrm{kg} / \mathrm{h}$, and the animals breathed spontaneously. Then they were immersed to the chin in water at $45^{\circ} \mathrm{C}$. When the Tep reached $42^{\circ} \mathrm{C}$ it was maintained by adjusting water bath temperature. Tep $42^{\circ} \mathrm{C}$ was maintained until cardiac arrest, defined as MAP $<25 \mathrm{~mm} \mathrm{Hg}$, absence of arterial pulsations, apnea, and EEG silence.

One min after cardiac arrest, CPR, ALS, and cooling were started. The hot water was rapidly drained, and the monkeys were subjected to standard CPR-ALS with i.v. fluids and vasopressors, and external electric countershocks as needed. During and after these CPR-ALS efforts, six monkeys (group I) were cooled by the application of ice bags only, one to each groin and each axilla, and two to the neck. The other six monkeys (group II) received ice bags as in group I, and in addition were sponged with cold water $\left(10-15^{\circ} \mathrm{C}\right)$ on the entire anterior skin surface of trunk and extremities, plus continuous use of an electric fan (standard 12 inch diameter household item). The air flow from the fan (about $1 \mathrm{~m}$ from and at the same level as the animal) was at room temperature, at maximal speed. Room temperature was $24^{\circ} \mathrm{C}$, humidity $40-45 \%$. Cooling was continued in both groups to and beyond restoration of spontaneous circulation until a $\operatorname{Tr}$ of $38.5^{\circ} \mathrm{C}$ was reached. If spontaneous circulation was not restored after $30 \mathrm{~min}$ of CPR-ALS plus cooling, or if irreversible rearrest occurred, resuscitation efforts were discontinued. The data were compared statistically using Student's $t$ test; $p<$ 0.05 was considered significant.

\section{RESULTS}

In the 12 pigtail monkeys, controlled Tep reached $42^{\circ} \mathrm{C}$ after $55 \mathrm{~min}$ of heating; when $\operatorname{Tr}$ was $42.7 \pm 0.4^{\circ} \mathrm{C}$. Cardiac arrest occurred after heating for $178 \pm 26 \mathrm{~min}$. Three animals arrested with ventricular fibrillation and nine with electromechanical dissociation leading to asystole. They did not differ between the chosen treatment groups and there was no difference from those animals that could not be resuscitated. At the time of cardiac arrest, group I had reached a Tep of $42.7 \pm 0.7^{\circ} \mathrm{C}$ and a $\mathrm{Tr}$ of $42.5 \pm 1.0^{\circ} \mathrm{C}$; and group II a Tep of $41.9 \pm 0.6^{\circ} \mathrm{C}$ and a $\mathrm{Tr}$ of $43.1 \pm 1.1^{\circ} \mathrm{C}(\mathrm{NS})$.

In group I, after CPR (maximum $30 \mathrm{~min}$ ) plus cooling with ice bags, spontaneous circulation was restored in four of six monkeys, after CPR of $6.6 \pm 6.4(1.5-16 \mathrm{~min})$. In group II, after CPR plus cooling with ice bags, sponging, and fanning, sponta- neous circulation was restored also in four of six monkeys, after CPR of $5.1 \pm 2.0(3.5-8)$ min (NS). Restoration of heart beat occurred with $\operatorname{Tr} 39-42^{\circ} \mathrm{C}$. $\operatorname{Tr}$ of $38.5^{\circ} \mathrm{C}$ was reached after restoration of spontaneous circulation, in group I within $45 \pm 6$ (38-53) min and in group II within $28 \pm 4(23-32) \min (p<$ $0.05)$.

Both cooling methods effectively lowered Tep and Tes. Reductions in Tep and Tes followed a similar course, but $\mathrm{Tr}$ declined more slowly. After cooling for $15 \mathrm{~min}$, both groups combined reached Tep $38.6 \pm 3(37.2-39.5)^{\circ} \mathrm{C}$ (Fig. 1). The rate of decline of Tep and Tes was numerically, but not statistically more rapid in group II than in group I. For Tr, however, group II at $30 \mathrm{~min}$ of cooling reached $38.4 \pm 0.2(38.2-40.6)^{\circ} \mathrm{C}$, whereas in group I at the same time $\mathrm{Tr}$ had declined to only $39.6 \pm 0.6$ $(38.2-41.5)^{\circ} \mathrm{C}(p<0.05)$ (Fig. 2). Normal EEG activity returned in three of the four resuscitated group I monkeys after $60 \pm 48$ (10-110) min of combined CPR and cooling time, and in the four resuscitated group II monkeys after $53 \pm 33(3.5-80) \mathrm{min}$ (NS). After successful CPR and spontaneous normotension, a secondary shock state developed in all transient survivors. Survival time was longer in group II. Secondary cardiac arrest occurred in group I after $119 \pm 17(122-132) \mathrm{min}$ and in group II after $199 \pm 26(170-222) \min (p<0.02)$. Two animals (one of each group) died with sudden ventricular fibrillation, the rest died with electromechanical dissociation leading to asystole.

\section{DISCUSSION}

In our model of hyperthermic cardiac arrest in pigtail monkeys, the combination of cooling by application of ice bags to the groins, axillae, and neck, plus continuous fanning of wetted (sponged) skin over the anterior aspects of trunk and extremities (group II) was significantly more effective than the use of ice bags alone (group I). The desired $\operatorname{Tr}$ of $38.5^{\circ} \mathrm{C}$ was reached in group II in significantly less time than in group I. Moreover, after cooling of 15 min, mean Tr of group II had decreased to $39.3 \pm 0.5^{\circ} \mathrm{C}$, whereas Tr of group I was still high $\left(41.5 \pm 0.5^{\circ} \mathrm{C}\right)$ $(p<0.05)$.

Cooling methods have been compared in animals and patients (34-36). Methods for wide clinical readiness and use should not require expensive special equipment and should not interfere with monitoring and resuscitation. Immersion of head and neck in an ice water-filled bag or box (of the intubated subject) (37, 38) could easily be added for greater effectiveness to total body surface cooling. Lees et al. (34) compared cooling rates in humans with application of ice bags alone versus fanning alone and found no significant difference. In our study, the two methods combined were compared with one alone, and the combination was found to be more effective.

Fanning is evaporative cooling, which is based on the fact that the evaporation of $1 \mathrm{~g}$ of water requires seven times as much latent heat as the melting of $1 \mathrm{~g}$ of ice. Khogali and Weiner (39) achieved maximum evaporative cooling rates by wetting the skin with a fine spray of water under pressure at $15^{\circ} \mathrm{C}$ while directing warm air onto the skin. They speculated that by keeping the skin warm and well perfused, it is possible to maintain a high watervapor pressure gradient from blood to skin to air, thereby facilitating heat loss. The amount of blood circulating in contact to the surface area is greater in warm than in cold skin. In newborns and children, as in the primates in our study, the ratio of skin surface area to body wt is relatively high. Use of ice bags or cold blankets, and cold water immersion, produce cooling by conduction. This alone may produce regional vasoconstriction that interferes with heat conduction. One must be cautious using ice bags in infants and small children. Covering most of the body surface would risk local cold injury (29).

We have found monkeys suitable as a model of hyperthermia (33). Dogs and some other animals have a brain cooling system that prevents overheating. Tep was initially more stable during heating in monkeys than in dogs. As heat immersion proceeded 


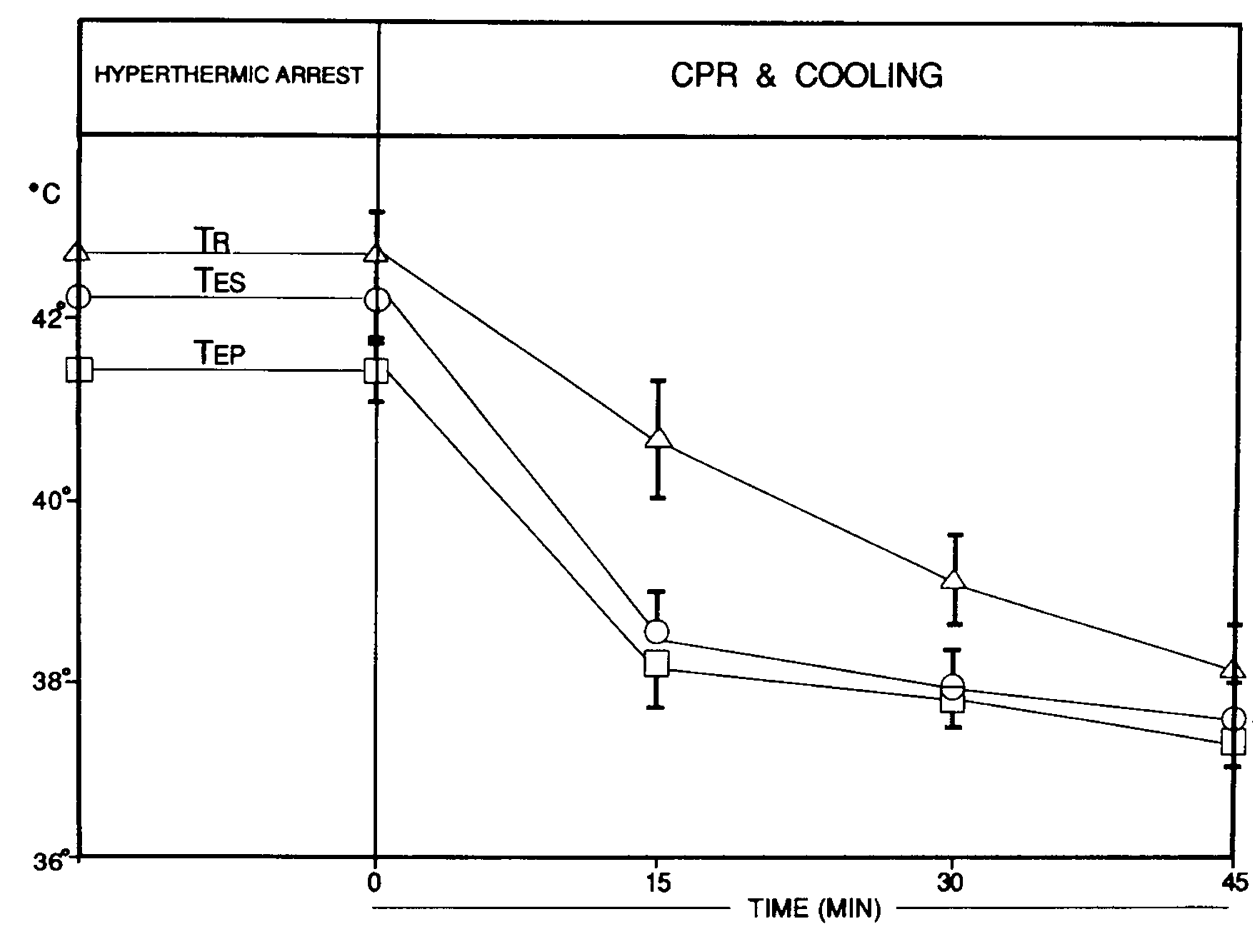

Fig. 1. Different temperatures in hyperthermia-induced cardiac arrest ( $1 \mathrm{~min}$ ) reversed by CPR to restoration of spontaneous normotension (at 1.5-16 min CPR), accompanied by surface cooling started simultaneously with CPR at time 0 , in eight monkeys. Time $0=$ start of cooling and CPR.

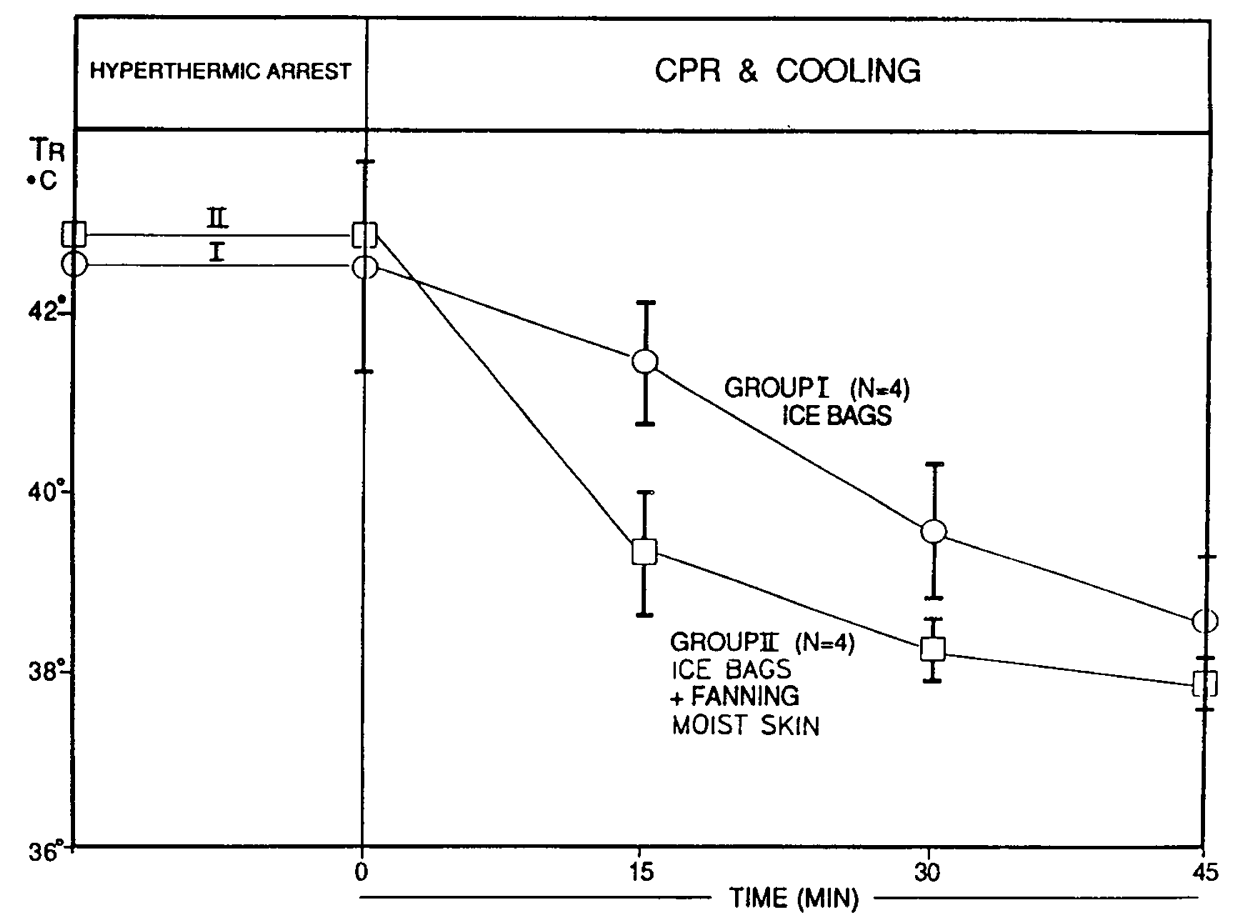

Fig. 2. $\mathrm{Tr}$ in hyperthermia-induced cardiac arrest ( $1 \mathrm{~min}$ ) reversed by CPR to restoration of spontaneous normotension (at $1.5-16 \mathrm{~min}$ CPR), accompanied by surface cooling with different methods, in eight monkeys. Group I, cooling by application of ice bags only. Group II, cooling by ice bags plus fanning of moist (sponged) skin.

and arterial pressure decreased, there was a slight relative decrease in Tep, possibly as a result of interference with heat transport via the circulation (40). Tr is closely correlated to visceral $\mathrm{T}(41)$, which might be crucial for posthyperthermia shock (33). Also, the use of $\operatorname{Tr}$ to measure the efficiency of cooling is clinically relevant, because $\operatorname{Tr}$ is most frequently monitored in small children and in critically ill patients of any age (41). Tes depends on closeness of the sensor to the trachea. In our study Tes did not differ significantly from Tep (brain surface). Invasively monitored patients can have core temperature (central venous or pulmonary artery $\mathrm{T}$ ) monitored and controlled. In our hypothermia animal research (37) central venous or pulmonary artery $T$ were the same as deep brain $T$, whereas Tes and Tep were $0.5-1.0^{\circ} \mathrm{C}$ lower, at $\mathrm{T}$ fluctuating between 34 and $38^{\circ} \mathrm{C}$.

Heat-related medical emergencies require prompt diagnosis and treatment, because capillary and vital organ cell damage are 
determined by the duration and the degree of hyperthermia ( 18 , 19, 33). Morbidity and mortality rates have been higher when cooling was delayed or inefficient $(20,21)$. Prompt reversal of hyperthermia alone may correct pathophysiologic states such as hypotension, arrhythmias, and convulsions $(18,19,23)$. In our study, the combination of ice bag application with continuous fanning of the wetted anterior skin surface, resulted not only in more rapid cooling, but also in earlier hemodynamic and neurologic (EEG) recovery than cooling with ice bags alone. In hyperthermia-induced cardiac arrest, during the first 5-10 min of CPR-ALS, both cooling methods had barely begun to lower $\mathrm{Tr}$ and Tep, while spontaneous circulation was restored during still moderate hyperthermia. It, therefore, comes as no surprise that CPR-ALS times were the same in the two groups, among those successfully resuscitated. The importance of rapid cooling, however, is underlined by our CPR results in hyperthermic cardiac arrest.

Lowering of core temperature should be perhaps extended below $38.5^{\circ} \mathrm{C}$, namely to about $35^{\circ} \mathrm{C}$, which we found recently to have a resuscitative effect after normothermic arrest (37).

We recommend, for use in hyperthermic crises, to have a safe system of cooling that does not interfere with monitoring and resuscitation routinely available, such as a combination of total body surface cooling by ice bags, skin wetting and fanning, and head cooling.

\section{REFERENCES}

1. Stanton AN 1984 Sudden infant death, overheating and cot death. Lancet 1:1199-1201

2. Committee of School Health 1984 Heat stress and school closing. Pediatrics $74: 313-314$

3. Whittington LK, Roscelli JD, Parry WH 1985 Hemorrhagic shock and encephalopathy: further description of a new syndrome. J Pediatr 106:599602

4. Sofer S, Phillip M, Hershkowits J, Bennett H 1986 Hemorrhagic shock and encephalopathy syndrome. Its association with hyperthermia. Am J Dis Child 140:1252-1254

5. Daily WJR, Klaus M, Meyer HBP 1969 Apnea in premature infants: monitoring, incidence, heart rate changes and an effect of environment temperature. Pediatrics 43:510-518

6. Perlstein PH, Edwards NK, Sutherland JM 1970 Apnea in premature infants and incubator-air-temperature changes. N Engl J Med 282:461-466

7. Mayock ED, McMillan DO 1986 Neonatal hyperthermia secondary to a plastic thermal blanket. Crit Care Med 14:817-818

8. Danks DM, Webb DW, Allen J 1962 Heat illness in infants and young children, a study of 47 cases. Br Med J 2:287-293

9. Editorial 1980 Overheated infants. Emerg Med 12:63-64

10. Ellis FP 1972 Mortality from heat illness and heat-aggravated illness in the United States. Environ Res 5:1-58

11. Bacon CJ, Scott D, Jones F 1979 Heatstroke in well wrapped infants. Lancet $1: 422-425$

12. Bacon CJ, Bellman MH 1983 Heatstroke as a possible cause of encephalopathy in infants. Br Med J 287:328(abstr)
13. Bacon CJ 1985 Overheating and the hemorrhagic shock and encephalopathy syndrome. J R Soc Med 78:175-176

14. American Academy of Pediatrics, Committee on Sport Medicine 1983 Thermoregulation and fluid and electrolytes needs. In: Smith NJ (ed) Sports Medicine: Health Care for Young Athletes. American Academy of Pediatrics, Evanston, IL, pp 142-160

15. Wadlington WB, Tucker AL, Fly F, Green HL 1976 Heat stroke in infancy. Am J Dis Child 130:1250-1251

16. King K, Negus K, Vance JC 1981 Heat stress in motor vehicles: a problem in infancy. Pediatrics 68:579-582

17. Surpure JS 1982 Heat-related illness and the automobile. Ann Emerg Med 11:263-265

18. Shibolet S, Lancaster MC, Baron Y 1976 Heatstroke: A review. Aviat Space Eviron Med 47:280-300

19. Knochel JP 1974 Environmental heat illness. Arch Intern Med 133:841-864

20. White JD, Riccobene E, Nucci R, Johnson C, Butterfield AB, Kamath R 1987 Evaporation versus iced gastric lavage treatment of heatstroke: comparative efficacy in a canine model. Crit Care Med 15:748-750

21. Wyndham CH, Strydom NB, Cook HM, Maritz JS, Morrison JF, Fleming PW, Ward JS 1959 Methods of cooling subjects with hyperpyrexia. J Appl Physiol 14:771-776

22. Vicario SJ, Okabajue R, Halton T 1986 Rapid cooling in classic heat-stroke: effect on mortality rates. Am J Emerg Med 4:394-398

23. Editorial 1981 Management of heatstroke. Lancet 1:910-911

24. Goldfrank L, Osborn H 1977 Heat stroke. Hospital Phys 8:14-18

25. Costrini AM, Pitt HA, Gustafson AB, Uddin OE 1979 Cardiovascular and metabolic manifestations of heat stroke and severe heat exhaustion. Am J Med 66:296-302

26. Clowes GHA, O'Donnell TF 1974 Heatstroke. N Engl J Med 291:564-567

27. Weiner JS, Khogali M 1980 A physiological body cooling unit for treatment of heatstroke. Lancet 1:507-509

28. Morris CF 1984 Abnormalities in temperature regulation. In: Lewin LD, Morris CF, Moore CG (eds) A Practical Guide to Pediatric Intensive Care. CV Mosby, St. Louis, pp 121-123

29. Moss MH 1970 Alcohol induced hypoglycemia and coma caused by alcohol sponging. Pediatrics $46: 445-447$

30. Ferris EB, Blanckenhorn MA, Robinson HW, Cullen GE 1938 Heatstroke. Clinical and chemical observations on 44 cases. J Clin Invest 17:249-262

31. Syverud AS, Barker WJ, Amsterdam JT, Bills GL, Goltra DD, Armao JC Hedges JR 1985 Iced gastric lavage for treatment of heatstroke: efficacy in a canine model. Ann Emerg Med 15:424-432

32. Bynum DG, Patton J, Bowers W 1977 An anaesthetized dog heatstroke model. J Appl Physiol 43:292-296

33. Sassano J, Eshel G, Safar P, Stezoski W 1981 Hyperthermic cardiac arrest in monkeys. Crit Care Med 9:409-410

34. Lees DE, Kim YD, Schuette W, Bull J, Whang-Pong J 1979 Causes of induced hyperthermia. Anesthesiology 50:69-70

35. Shvartz E, Ben-Mordechai Y, Aladjem M, Magazanik A 1976 Neck and back cooling in a hot environment. Isr J Med Sci 12:796-799

36. Epstein Y, Shapiro Y, Brill S 1986 Comparison between different auxiliary cooling devices in a severe hot/dry climate. Ergonomics 29:41-48

37. Leonov Y, Sterz F, Safar P, Radovsky A, Oku K, Tisherman S, Stezoski W 1990 Mild cerebral hyperthermia during and after cardiac arrest improves neurologic outcome in dogs. $J$ Cereb Blood Flow Metab (in press)

38. Brader EW, Jehle D, Safer P 1985 Protective head cooling during cardiac arrest in dogs. Ann Emerg Med 14:510(abstr)

39. Khogali M, Weiner JS 1980 Heatstroke: report on 18 cases. Lancet 2:276-298

40. Martin PA, Robins HI, Dennis WH 1987 Monitoring body site temperature during systemic hyperthermia. Crit Care Med 15:163-164

41. Webster HW 1984 Bioinstrumentation: principles and techniques. In: Hazinski MF (ed) Nursing Care of the Critically Ill Child. CV Mosby, St. Louis, pp $648-738$ 